\title{
Nutrient density: addressing the challenge of obesity
}

\author{
Adam Drewnowski* \\ Center for Public Health Nutrition, University of Washington, Seattle, WA 98195, USA \\ (Submitted 27 January 2017 - Final revision received 29 July 2017 - Accepted 2 August 2017- First published online 30 October 2017)
}

\section{Abstract}

Obesity rates are increasing worldwide. Potential reasons include excessive consumption of sugary beverages and energy-dense foods instead of more nutrient-rich options. On a per kJ basis, energy-dense grains, added sugars and fats cost less, whereas lean meats, seafood, leafy greens and whole fruit generally cost more. Given that consumer food choices are often driven by price, the observed social inequities in diet quality and health can be explained, in part, by nutrition economics. Achieving a nutrient-rich diet at an affordable cost has become progressively more difficult within the constraints of global food supply. However, given the necessary metrics and educational tools, it may be possible to eat better for less. New metrics of nutrient density help consumers identify foods, processed and unprocessed, that are nutrientrich, affordable and appealing. Affordability metrics, created by adding food prices to food composition data, permit calculations of both kJ and nutrients per penny, allowing for new studies on the economic drivers of food choice. Merging dietary intake data with local or national food prices permits the estimation of individual-level diet costs. New metrics of nutrient balance can help identify those food patterns that provide optimal nutritional value. Behavioural factors, including cooking at home, have been associated with nutrition resilience, defined as healthier diets at lower cost. Studies of the energy and nutrient costs of the global food supply and diverse food patterns will permit a better understanding of the socioeconomic determinants of health. Dietary advice ought to be accompanied by economic feasibility studies.

\section{Key words: Obesity: Energy density: Nutrient density: Affordable nutrition index: Nutrient-rich diets: Ultra-processed foods}

The key elements of the global obesity challenge are these. First, the global food supply has been structured to maximise inexpensive $\mathrm{kJ}$ from staple grains, vegetable oils and sugar crops $^{(1)}$. Second, the food industry has produced many energydense and good-tasting foods that can contain excess solid fat, sugar or salt ${ }^{(2-5)}$. Third, energy-dense processed and packaged foods tend to be cheaper and more convenient than foods that are perishable and farm-fresh. Fourth, people eat what they can afford $^{(6,7)}$. Lower-cost foods and lower-cost diets are more likely to be consumed by lower-income groups ${ }^{(6)}$. Not by coincidence, lower-income groups have lower-quality diets and are more likely to be diabetic or obese $\mathrm{c}^{(6,8)}$.

High sensory appeal, low cost, wide availability and large portions of energy-dense foods can promote overeating and weight gain ${ }^{(6,7)}$. Previous studies have noted strong associations between dietary energy density and obesity ${ }^{(9-11)}$ and type 2 diabetes $^{(12,13)}$. Among potential mechanisms linking dietary choices and health outcomes were high glycaemic index, low fibre content and high reward value of energy-dense foods ${ }^{(12-15)}$. Short-term feeding studies suggested that lowerenergy-density food choices can result in lower energy intakes $^{(13)}$. The 2010 Dietary Guidelines Advisory Committee concluded that reducing dietary energy density improved weight maintenance and weight loss ${ }^{(13)}$.

What needs to be recognised is that dietary energy density and dietary nutrient density are inversely linked ${ }^{(16)}$. Reducing dietary energy density ${ }^{(13-15)}$ usually encompasses increasing dietary nutrient density, whether for weight management or public health purposes. Whereas energy density is simply defined as kcal/100 g (or kJ/100 g), metrics of nutrient density rely on more complex nutrient profiling (NP) methods ${ }^{(17,18)}$. The goal of NP models is to separate foods, meals or food patterns into those that are energy-dense and those that are nutrient rich ${ }^{(19)}$. Unfortunately, higher-quality food patterns are often associated with higher per kJ diet costs ${ }^{(20,21)}$.

Most dietary guidelines are silent on the fundamental issue of diet cost $^{(22)}$. For example, the United States Department of Agriculture (USDA) Healthy Food Patterns, a part of the 2015 Dietary Guidelines for Americans (DGA) ${ }^{(22)}$, featured Healthy US, Healthy Vegetarian and Healthy Mediterranean patterns. The patterns specified the amounts of leafy green vegetables, whole fruit and seafood that ought to be included in a healthy diet, without much concern for their likely higher cost. Whereas energy-dense diets cost less, the recommended higher-quality

Disclaimer: This article was published as part of the WALTHAM International Nutritional Sciences Symposium Proceedings 2016. This paper was published as part of a supplement to British Journal of Nutrition. The papers included in this supplement were invited by the Guest Editor and have undergone the standard journal formal review process. They may be cited.

Abbreviations: NP, nutrient profiling; USDA, United States Department of Agriculture.

* Corresponding author: A. Drewnowski, email adamdrew@uw.edu 
diets are likely to cost more ${ }^{(20,21)}$. Indeed, the defining characteristic of energy-dense diets may not be their sugar or fat content but their lower cost per $\mathrm{kJ}^{(23)}$. Arguably, taxation measures imposed on low-cost sugary beverages, fats and sweets implicitly recognise the economic roots of social disparities in diets and health ${ }^{(24)}$.

\section{Obesity, energy and nutrients}

The regular disagreements whether it is dietary sugar or dietary fat that drives the obesity epidemic can be viewed through the prism of energy costs. Both low-energy-density sugary beverages and high-energy-density snacks and fast foods have been listed as likely culprits, although at different times ${ }^{(23)}$. Whereas both science and popular opinion were once resolutely against dietary fat, they are now against added sugar. It bears repeating that lowenergy-density sugary beverages and high-energy-density snacks have little in common, other than their low per $\mathrm{kJ}$ cost ${ }^{(23)}$. Their palatability, satiety, glycaemic index and fibre content are all vastly different. Reducing dietary energy density meets the twin objectives of reducing energy intakes and improving the nutrients: energy content ratio ${ }^{(13)}$. It is currently viewed as an emerging approach to weight management ${ }^{(12)}$.

The present position is that improving dietary nutrient density, defined here as the nutrients:energy ratio, can be viewed as an approach to weight management in its own right. Whereas energy-dense diets have been repeatedly linked to obesity risk, nutrient-rich diets (roughly their reciprocal) have not. It is worth noting, in this context, that lower-income groups that are most likely to be overweight or obese are also most likely to exhibit nutrient deficiencies ${ }^{(25)}$. In other words, it has become possible to be undernourished yet overfed. The term 'hidden hunger' ${ }^{\text {(25) }}$, only recently linked to obesity risk, refers to shortfalls in dietary intakes of vitamins and minerals, most often found among low-income and other vulnerable groups.

These observations run counter to the long-standing dogma of nutritional epidemiology, which is that all dietary nutrients are positively correlated with total energy intakes. The low cost of excess energy from plant foods (sugar cane, soya and maize are all plants) has led to the uncoupling of the key relation between $\mathrm{kJ}$ and nutrients. Attempts to reduce diet costs steer consumers towards lower-cost high-energy foods, leading to diets that are energy-rich but nutrient-poor. In that case, eating more empty kJ from 'junk' foods would not necessarily yield any additional nutrients.

\section{What is energy density?}

In general, energy-dense foods are foods that are dry. It is water content, rather than the content of fat and sugar, that drives the energy density of beverages and foods ${ }^{(23)}$. The energy density range runs from water $(0 \mathrm{kcal} / \mathrm{g}$ or $0 \mathrm{~kJ} / \mathrm{g}$ ) to sugar $(4 \mathrm{kcal} / \mathrm{g}$ or $17 \mathrm{~kJ} / \mathrm{g}$ ) to fat $(9 \mathrm{kcal} / \mathrm{g}$ or $38 \mathrm{~kJ} / \mathrm{g}$ ). Even though recent studies may have referred to 'energy-dense' sugary beverages and 'lowenergy-density' beans or whole grains ${ }^{(13)}$, such statements are the opposite of the truth. Despite being the major source of added sugars in the US diet, sugary beverages have low energy density, in the order of $40 \mathrm{kcal} / 100 \mathrm{~g}$, same as baby carrots.

The relation between mean energy density of foods (kcal/100 g) and their mean water content $(\mathrm{g} / 100 \mathrm{~g})$ is shown in Fig. 1. The data are for 7162 foods in the Food and Nutrient Database for Dietary Studies (FNDDS 2009-2010), aggregated to nine major USDA food groups. The size of the bubble reflects the number of FNDDS foods within each of the nine food groups. FNDDS data are used to calculate calories and nutrients in the What we Eat in America studies.

Fig. 2 shows the relation between mean energy cost of foods $(\$ / 100 \mathrm{kcal})$ and their mean water content $(\mathrm{g} / 100 \mathrm{~g})$. It can be seen that grains, fats and oils cost less per $\mathrm{kJ}$ than do vegetables, fruit or meat, poultry and fish. The data are for 5319 foods in FNDDS 2009-2010 for which national food prices were available, adjusting for inflation.

Reducing dietary energy density, as opposed to focusing on either sugar or fat, is viewed as an emerging approach to weight

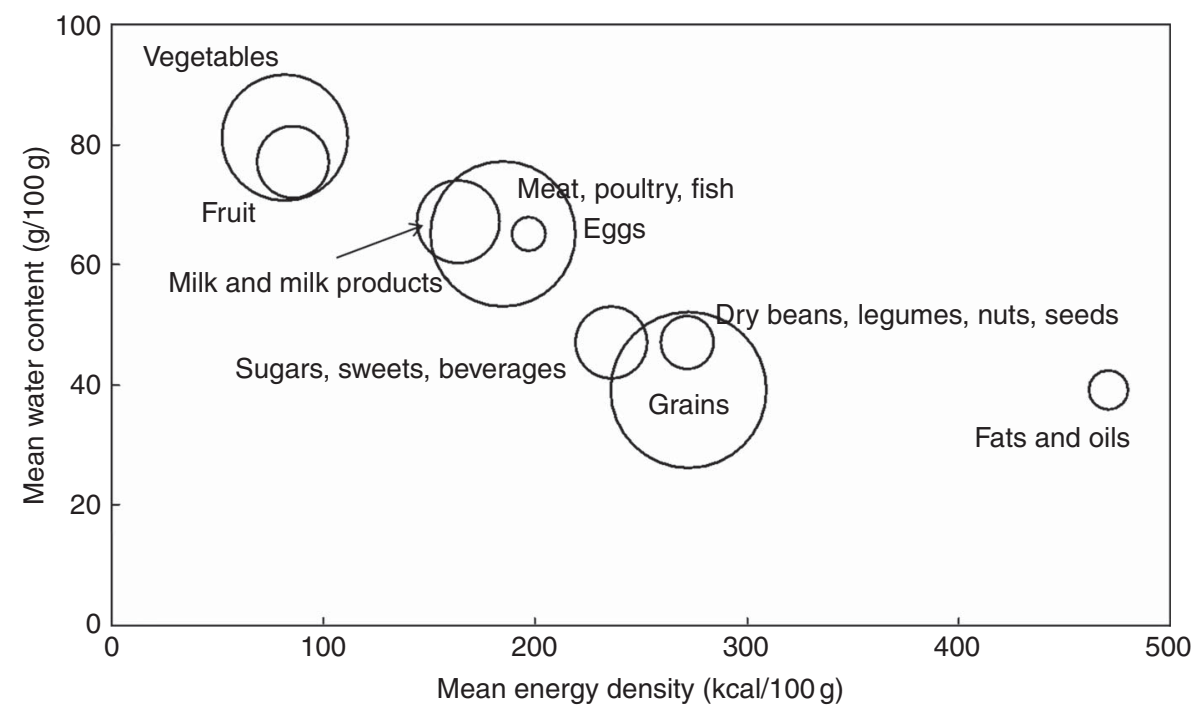

Fig. 1. Relation between mean energy density (kcal/100 g) and mean water content of foods ( $\mathrm{g} / 100 \mathrm{~g}$ ) by United States Department of Agriculture nine major food groups. Data are for 7162 foods in the Food and Nutrient Database for Dietary Studies (2009-2010). Size of the bubble denotes the number of foods per major food group. 


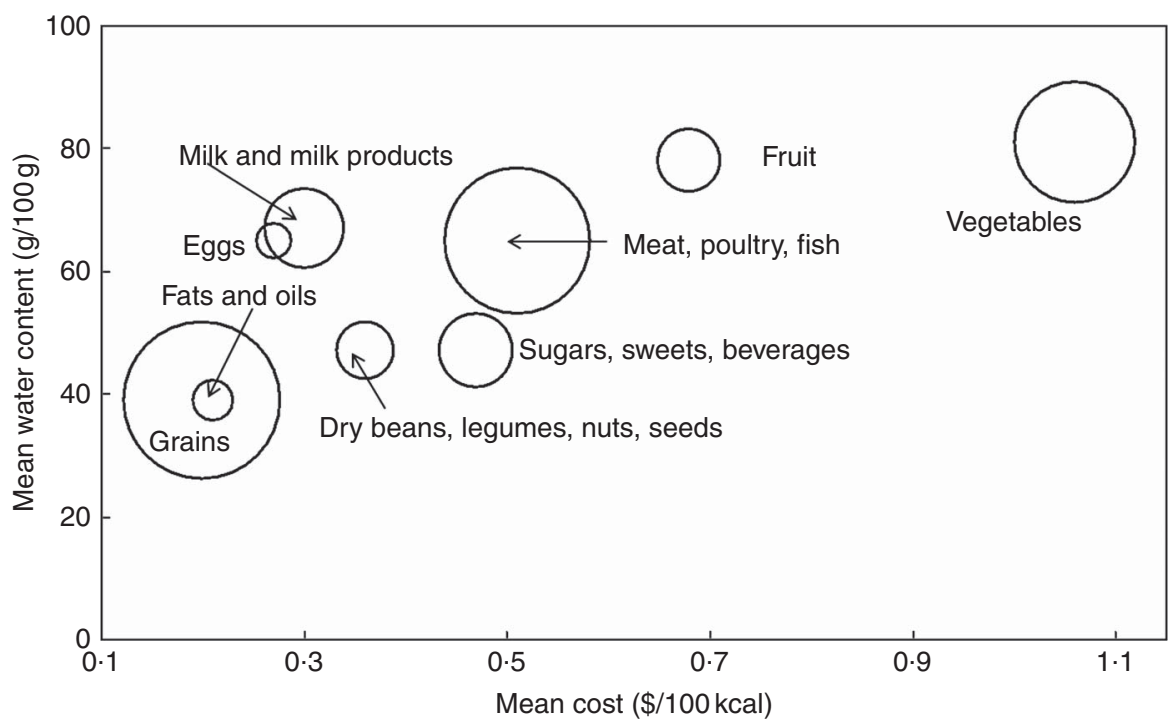

Fig. 2. Relation between mean cost per $100 \mathrm{kcal}(\$ / 100 \mathrm{kcal})$ and mean water content of foods $(\mathrm{g} / 100 \mathrm{~g})$ by United States Department of Agriculture nine major food groups. Data are for 5319 foods in the Food and Nutrient Database for Dietary Studies (2009-2010). Size of the bubble denotes the number of foods per major food group. To convert kcal to kJ, multiply by 4.18 .

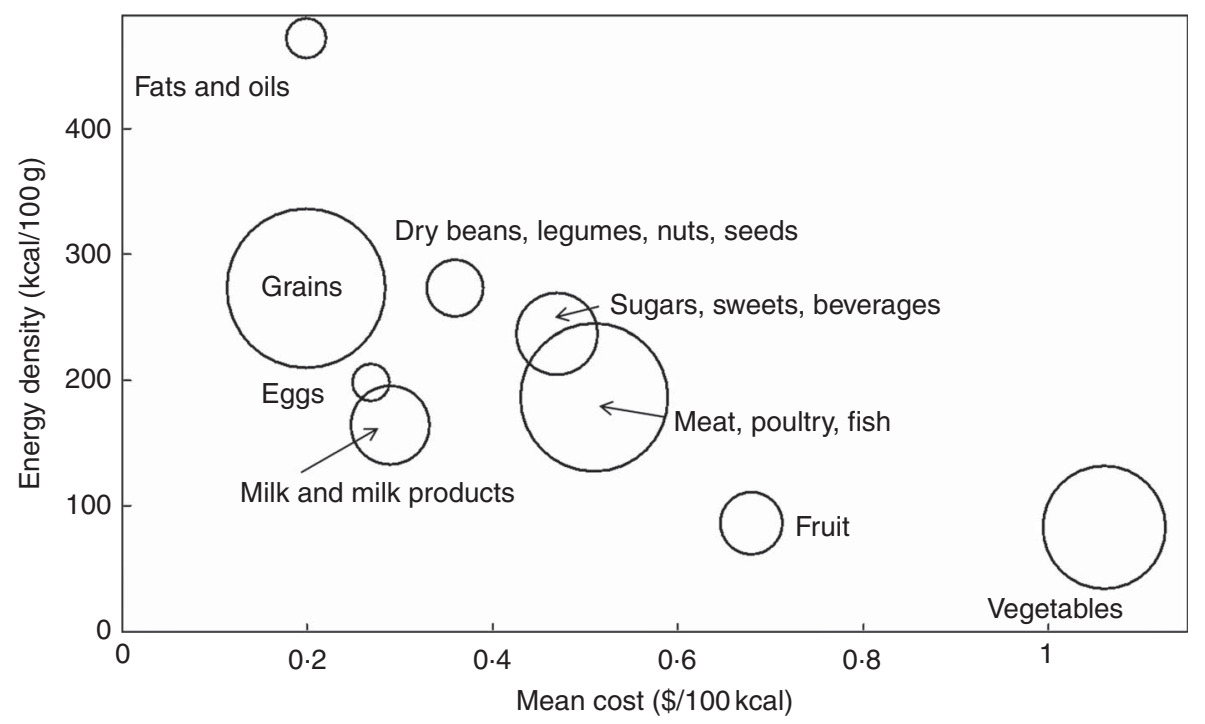

Fig. 3. Relation between mean cost per $100 \mathrm{kcal}(\$ / 100 \mathrm{kcal})$ and mean energy density of foods $(\mathrm{kcal} / 100 \mathrm{~g})$ by United States Department of Agriculture nine major food groups. Data are for 5319 foods in the Food and Nutrient Database for Dietary Studies (FNDDS 2009-2010). Size of the bubble denotes the number of foods per major food group. To convert kcal to kJ multiply by 4.18 .

management $^{(13)}$. The World Health Organization report ${ }^{(15)}$, published in 2006, also identified dietary energy density as a key factor. Dietary energy density can be reduced by lowering the diet's content of fat $(9 \mathrm{kcal} / \mathrm{g}$ or $38 \mathrm{~kJ} / \mathrm{g}$ ) and/or dry grains ( $4 \mathrm{kcal} / \mathrm{g}$ or $17 \mathrm{~kJ} / \mathrm{g}$ ) and by increasing the consumption of moisture-containing vegetables and whole fruit $(<1 \mathrm{kcal} / \mathrm{g}$ or $<4 \cdot 18 \mathrm{~kJ} / \mathrm{g})^{(14)}$. One advantage of reducing dietary energy density was that the volume of bulky, low-energy-density diets has been linked to increased satiety, the feeling of being full after fewer $\mathrm{kJ}^{(14)}$. Paradoxically, consuming more low-energydensity beverages did not count. Beverages, whether energetic or non-energetic, do not enter into most dietary energy density calculations, and neither does drinking water.
As might be expected, diets containing fewer $\mathrm{kJ}$ per gram tend to contain more nutrients per kJ. However, replacing energy-dense grains, fats and sweets with equienergetic but healthier options does increase diet cost. Fig. 3 shows the relation between mean energy density $(\mathrm{kcal} / 100 \mathrm{~g}$ ) of foods and their mean energy cost $(\$ / 100 \mathrm{kcal})$. Energy-dense fats and oils, as well as grains, were cheaper per $\mathrm{kJ}$ than were low-energy-density vegetables and fruit.

Given that getting maximum perceived kJ per unit cost is the prime driver of food choices for the low-income consumer $^{(26)}$, eating more vegetables and fruit may not be a viable dietary advice. The unwillingness to buy expensive perishable foods can steer many food insecure households towards more 
shelf-stable options, especially when shopping is limited to once or twice per month. Although food prices may be one obstacle, additional factors may include accessibility, food distribution and retail, and food storage, as well as factors related to food preservation and safety, cooking skills or preparation time. The entry of women into the global labour force, in particular, has led to increased reliance on time-saving processed and fast foods ${ }^{(27)}$.

Food stamp recipients in the USA have been criticised for selecting sweetened beverages and energy-dense desserts, salty snacks, candy and sugar instead of the more nutritious but perishable foods such as fruit and vegetables, eggs and beans, nuts and seeds ${ }^{(28)}$. Despite the USDA conclusion that both food stamp recipients and other households generally made similar purchases, experts suggested policing food choices of low-income groups to ensure more purchases of healthier, if more expensive, foods ${ }^{(28)}$.

\section{Food processing, energy density and cost}

On the basis of current definitions ${ }^{(29,30)}$, unprocessed or minimally processed foods include fresh, dry and frozen fruit or vegetables, grains, legumes and fresh meat, fish and milk. Processed culinary ingredients include table sugar, oils, animal fats and salt. Simply processed foods, produced by adding fat, sugar or salt to minimally processed foods, include simple breads, ham and cheese. Ultra-processed foods, the fourth category, were defined as industrial formulations that contained cost per $100 \mathrm{kcal}^{*}$ added salt, sugar, oils and fats, as well as substances that had been added to mimic the taste appeal of fresh foods. Among those substances were flavours, colours, sweeteners, emulsifiers and other additives that were not used in culinary preparations, as would normally be undertaken at home.

As might be expected, most grain-based products automatically fall into the ultra-processed category. Grains are not normally consumed raw; to prepare bread, pasta, oatmeal, breakfast cereals or tortillas, some degree of processing is involved. Furthermore, most refined grains are enriched such that B vitamins (thiamin, riboflavin, niacin, folic acid) and Fe are added back after milling and processing. Ironically, the MyPlate advice to consume more whole-grain breads or cereals can be viewed as an invitation to eat more ultraprocessed foods.

A direct comparison of selected unprocessed and ultraprocessed food groups on energy density (kcal/100 g), cost per $100 \mathrm{~g}$ and cost per $100 \mathrm{kcal}$ is shown in Table 1 . Energy density data were obtained from the USDA FNDDS 2009-2010. Food prices per $100 \mathrm{~g}$ of edible portion were obtained from the USDA national food prices database and were adjusted for inflation. Analyses were restricted to foods listed more than 20 times on the 1st day of recall in the National Health and Nutrition Examination Survey 2009-2010 (NHANES 2009-2010). Food categories were based on the National Cancer Institute food aggregation scheme ${ }^{(31)}$.

Table 1. A comparison of selected unprocessed and ultra-processed food groups on energy density (kcal/100 g), cost per $100 \mathrm{~g}$ and

\begin{tabular}{|c|c|c|c|c|c|}
\hline Food groups & $\begin{array}{l}\text { Example from FNDDS } \\
2009-2010\end{array}$ & Items $(n)$ & $\begin{array}{l}\text { Energy density } \\
(\mathrm{kcal} / 100 \mathrm{~g})\end{array}$ & $\begin{array}{c}\text { Cost } \\
(\$ / 100 \mathrm{~g})\end{array}$ & $\begin{array}{c}\text { Cost } \\
(\$ / 100 \mathrm{kcal})\end{array}$ \\
\hline \multicolumn{6}{|l|}{ Unprocessed foods } \\
\hline Milk and plain yogurt & Milk, whole fat & 1 & 61 & 0.16 & 0.25 \\
\hline Meat & Beef, excludes ground & 5 & 219 & 1.33 & 0.64 \\
\hline \multirow[t]{2}{*}{ Fish and seafood } & Fish & 1 & 182 & 1.30 & 0.72 \\
\hline & Shellfish & 3 & 167 & 2.46 & $2 \cdot 10$ \\
\hline Eggs & Eggs and omelettes & 9 & 171 & 0.28 & 0.17 \\
\hline Legumes & Beans, peas, legumes & 6 & 133 & 0.35 & 0.24 \\
\hline \multirow{2}{*}{ Fruit } & Berries & 2 & 44 & 0.66 & 1.55 \\
\hline & Citrus & 2 & 50 & 0.52 & 1.08 \\
\hline Roots and tubers & Carrots & 2 & 38 & 0.25 & 0.65 \\
\hline \multirow[t]{3}{*}{ Vegetables } & Lettuce and salads & 3 & 17 & 0.42 & 2.49 \\
\hline & Dark green vegetables & 3 & 31 & 0.67 & $2 \cdot 31$ \\
\hline & Red, orange vegetables & 1 & 31 & 0.41 & 1.33 \\
\hline \multicolumn{6}{|l|}{ Ultra-processed foods } \\
\hline Milk-based drinks & Flavoured milk, low fat & 1 & 63 & 0.09 & 0.15 \\
\hline Ice cream & Ice cream & 6 & 232 & 0.48 & 0.20 \\
\hline Meat products & Frankfurters & 4 & 290 & 0.51 & 0.18 \\
\hline Hamburgers & Burgers & 3 & 265 & 0.36 & 0.13 \\
\hline Breads & Biscuits, muffins & 5 & 334 & 0.38 & 0.11 \\
\hline Cakes, cookies, pies & Cakes and pies & 4 & 386 & 0.53 & 0.14 \\
\hline Salty snacks & Potato chips & 4 & 515 & 0.92 & 0.18 \\
\hline Sweet snacks & Candy, chocolate & 8 & 515 & 0.84 & $0 \cdot 16$ \\
\hline Breakfast cereals RTE & RTE cereal, low sugar & 10 & 377 & 0.66 & $0 \cdot 17$ \\
\hline French fries & French fries & 7 & 247 & 0.38 & 0.15 \\
\hline Pizza RTE & Pizza & 7 & 290 & 0.84 & 0.29 \\
\hline Fruit drinks & Fruit drinks & 11 & 45 & $0 \cdot 10$ & 0.24 \\
\hline Soft drinks, carbonated & Soft drinks & 7 & 39 & 0.08 & 0.21 \\
\hline Desserts & Doughnuts, pastries & 7 & 389 & 0.47 & 0.12 \\
\hline
\end{tabular}

FNDDS, Food and Nutrient Database for Dietary Studies; RTE, ready-to-eat; NHANES, National Health and Nutrition Examination Survey.

* Energy density data from FNNDS 2009-2010. Cost data from United States Department of Agriculture national food prices database, adjusted for inflation. Analyses restricted to foods listed more than 20 times on the 1st day of recall in the NHANES 2009-2010. Food categories based on the National Cancer Institute food aggregation scheme. To convert kcal to kJ, multiply by $4 \cdot 18$. 
Table 1 clearly shows that the ultra-processed foods, largely grains, were in general more energy-dense than were milk, fish, eggs, whole fruit or fresh produce. On a per kJ basis, the ultra-processed foods were also considerably less expensive. The current dismissal of ultra-processed foods as important sources of essential nutrients owes much to the failure to consider the basic economics of food choice behaviour.

Unlike many fresh foods, processed foods can be reformulated to improve their nutritional quality and the nutrient:energy content ratio ${ }^{(16)}$. The food industry has been using NP to improve the nutrient density of product portfolios. The economic challenge is how to improve product nutrient density without increasing cost per nutrient.

Energy-dense foods need not always be nutrient-poor. Even though the inverse relation does hold, there are exceptions, notably dry beans, legumes, nuts and seeds, eggs and some milk products. Tree nuts, including almonds, as well as peanuts, pulses and legumes, not to mention fortified ready-to-eat cereals, have high energy density and high overall nutritional value. Dry cheeses are exceptionally rich in $\mathrm{Ca}$, whereas French fried potatoes are a major source of $\mathrm{K}$ in the American diet. Whereas dry whole-grain snacks are energy-dense, energy density of sugar-sweetened beverages is low.

Nonetheless, the energy density concept has recently been adapted for taxation purposes. Mexico recently imposed a tax on non-essential snacks with energy density exceeding $275 \mathrm{kcal} / 100 \mathrm{~g}$ or $1150 \mathrm{~kJ} / 100 \mathrm{~g}^{(22)}$ : tortillas, tamales and lard, which are the major sources of low-cost kJ among the Mexican poor, were exempted for cultural reasons. Included in the definition of non-essential foods were chocolate, potato chips and nuts but not the lower-energy-density ice cream. Sugary beverages were taxed, seemingly based on their sugar content and not energy density.

\section{Nutrient density of foods}

Unlike energy density, the definition of 'nutrient density' is open to multiple interpretations ${ }^{(17-19)}$. The concept of nutrient density was initially built around key nutrients contained in $100 \mathrm{kcal}$ (or $418 \mathrm{~kJ}$ ) of a given food ${ }^{(21)}$. Nutrient-dense foods were later described as those that contained more nutrients than kJ. Making that fuzzy definition more quantitative was the stated goal of early NP models. The main challenge was to select the most appropriate nutrients and the reference amounts.

Nutrient density of foods can be measured as nutrients per kJ, nutrients per serving or nutrients per $100 \mathrm{~g}$. NP models rank individual foods based on their nutrient content relative to $\mathrm{kJ}$ content. The goal of NP is to separate foods that are largely high in energy content from those that are nutrient-rich ${ }^{(20)}$.

Nutrient profile models distinguish between qualifying and disqualifying nutrients, sometimes referred to as shortfall nutrients, consumed in insufficient amounts, and nutrients of public health concern, often consumed in excess. Among the shortfall nutrients in the 2015 DGA were fibre, K, Ca and vitamin $\mathrm{D}$, since their consumption fell short of recommended values. By contrast, nutrients of public health concern generally include solid (or saturated) fats, added sugar and Na. Sugars can be included as total sugars, added sugars and free sugars. On the basis of the 2015 DGA, cholesterol was no longer a nutrient of concern.

The Nutrient Rich Foods (NRF) index, representing a family of scores, was based on a variable number of qualifying nutrients (nutrients to encourage) and on three disqualifying nutrients (nutrients to limit). In the NRF9.3 variant the qualifying nutrients were protein, fibre, $\mathrm{Ca}, \mathrm{Fe}, \mathrm{K}$ and $\mathrm{Mg}$, vitamin $\mathrm{A}$, vitamin $\mathrm{C}$ and vitamin $\mathrm{E}$. The disqualifying nutrients were saturated fat, added sugars and Na. The NRF9.3 algorithm was based on the sum of percent daily values (\%DV) for nine qualifying nutrients minus the sum of maximum recommended values for three disqualifying nutrients. The basis of calculation was per $100 \mathrm{kcal}$, or per $418 \mathrm{~kJ}$, or per serving, in contrast to the British FSA-Ofcom model that is based on $100 \mathrm{~g}^{(18)}$. Models based on nutrients per unit weight cannot readily deal with diverse portion sizes across different food groups. The FSA-Ofcom model captures the foods' energy density, and not their nutritional value ${ }^{(18)}$

Most foods contain multiple nutrients. Some NP models do not allow qualifying nutrients to compensate for excess fat, sugar and salt. The US FDA also disqualifies foods from nutrition and health claims if they contain the above-specified amounts of fat, saturated fat, trans-fat, cholesterol and $\mathrm{Na}$ per serving. For instance, a food that is high in total or saturated fat cannot claim to be 'low in Na'. The FDA prevents foods with an undesirable nutrient profile from making a nutrition and health claim by adjusting serving sizes. For foods with small serving sizes, the serving size defaults to $50 \mathrm{~g}$ if a nutrition claim is to be made. The potentially disqualifying nutrients are then calculated on a $50-\mathrm{g}$ basis.

In practice, some NP models are compensatory, whereas others are not. The NRF family of scores balances qualifying and disqualifying nutrients ${ }^{(18-20)}$, whereas the Nestlé Nutrition Profile does not ${ }^{(32)}$. Balanced or compensatory models allow qualifying nutrients to compensate for the presence of disqualifying ones. Protein, fibre, vitamins and minerals were able to compensate for the presence of fat, sugar and salt. In noncompensatory models, this is not allowed.

\section{Nutrient balance of composite meals and total diets}

Focusing on individual foods and beverages has generated some paradoxes. Some foods or foods groups score low, yet they contain essential nutrients that are indispensable to a healthy diet. The fats and oils category is one example: olive oil and other fats score low. On the other hand, some highly rated nutrient-dense foods do not contain sufficient $\mathrm{kJ}$ to meet energy requirements. This dietary energy needs to come from other, lower-rated foods to achieve the best nutrients-to-energy balance. In other words, whereas energy-dense foods may not be conducive to good health, a diet composed entirely of the most nutrient-rich foods may be incompatible with survival.

The concept of nutrient balance ${ }^{(22)}$ shifts the analytical focus from individual foods to combinations of foods as contained in composite meals, or daily food patterns. The overall quality of food patterns is based on qualifying and disqualifying nutrients, and also on the complementarity of the nutrients as achieved by some food combinations but not by others. In principle, 
balanced healthy food patterns can be arrived at using a wide variety of food combinations ${ }^{(23)}$. Those food patterns are very much dependent on societal factors, history and culture. For example, the current trends towards more convenient processed foods and fast foods eaten away from home cannot be separated from the entry of women into the labour force ${ }^{(27)}$. Local and regional food patterns will need to be included in the new generation of NP models.

Adaptations of nutrient profile models for lower-income countries will require adequate local or regional data on the nutrient composition of foods, dietary intakes and health outcomes. Potential NP models will be limited by the number of foods and nutrients that are included in the national or regional nutrient composition databases.

\section{New food affordability metrics}

The US 2015 DGA have identified solid fats and added sugars as the principal sources of empty $\mathrm{kJ}$ in the American diet. The population diet was too high in energy, saturated fats, added sugars and $\mathrm{Na}$. The advice was to consume more fibre, $\mathrm{K}, \mathrm{Ca}$ and vitamin $\mathrm{D}$, identified as shortfall nutrients of public health concern. Among the recommended food groups were whole fruits, leafy green vegetables, lean meats and seafood, low-fat dairy products and whole grains. However, close adherence to federal dietary guidelines was associated with higher diet costs to the consumer.

Despite denials, food prices remain an important driver of food choice. It is well known that food prices can be the primary determinant of food purchases, along with taste, convenience and perceived nutritional value. Paradoxically, many unhealthy foods are convenient, good-tasting and cost less, whereas some healthier foods can be hard to prepare, taste bad and cost more.

Once the nutrient density of foods is calculated per energy content or per serving, the relative affordability of foods can then be expressed as kJ or nutrients per penny ${ }^{(17,23,24)}$. The goal is to identify the most affordable items within each of the recommended food groups: vegetables, fruit, whole grains or low-fat dairy products.

On the basis of USDA national prices for ninety-eight vegetables, fresh, frozen and canned, a recent study ${ }^{(25)}$ calculated vegetable costs per $100 \mathrm{~g}$, per $100 \mathrm{kcal}$ and per edible cup. Nutrient density was based on a custom-created NP model that included fibre, vitamins $\mathrm{A}, \mathrm{C}$ and $\mathrm{K}, \mathrm{K}$ and $\mathrm{Mg}$. Nutrient affordability was the cost associated with the provision of $10 \%$ DV of each nutrient per cup equivalent.

A similar approach, applied to Ca value metrics for a wide range of milks and dairy products in France, showed that fluid milks, hard cheeses and low-fat yogurts delivered $\mathrm{Ca}$ at relatively low monetary cost and without excessive amounts of $\mathrm{kJ}$ or disqualifying nutrients ${ }^{(26)}$. Comparable value metrics are being developed for whole fruits and juices, dairy protein sources and whole grains.

\section{The relation between food patterns' quality and cost}

By emphasising nutrient content of individual foods, NP models have yielded some paradoxes. First, some 'good' foods (nuts, yogurt, cheese) can contain 'bad' nutrients, fat, sugar or salt. On the other hand, some of the highly ranked nutrient-rich foods do not contain sufficient energy content to meet energy needs. One petition before the US Food and Drug Administration is to base the definition of 'healthy' foods not on single nutrients but on food groups. Thus, some food groups (e.g. whole fruit, nuts and seeds) could be declared to be healthy regardless of their nutrient content.

More attention is also being paid to food patterns, as opposed to individual foods. Foods can contribute different amounts of nutrients to the diet, depending on local eating habits. The relative amounts of these nutrients in culturally appropriate food consumption patterns need to be taken into account in the new generation of NP. A shift in focus from judging individual foods to quantifying nutrient balance in meals and total diets would be helpful as well.

Merging retail prices with dietary intake data has allowed the estimation of diet costs at the individual level. Previously, data on food costs and food expenditures were collected not at the individual but at the household level. The methods take advantage of the USDA Center for Policy and Promotion national food prices database, which has been adjusted for inflation and merged with NHANES 2009-2010 ${ }^{(27)}$. The monetary value of the diet was then calculated by multiplying gram amounts of each food eaten by every NHANES participant by price per gram. These values were then summed for each participant.

Dietary guidelines have generally focused on the relation between diet quality metrics and selected health outcomes. The recent focus on sustainable diets has expanded the nutrition discourse to the diets' monetary and environmental cost. The four domains of sustainability are nutrition and health, economics, society and the environment. Mathematical modelling techniques, such as linear programming, have extended NP of foods to create sustainable food patterns for diverse population subgroups, subject to a variety of constraints. Their goal is to create food patterns that are simultaneously nutrient-rich, affordable, culturally acceptable and appealing. Helping consumers identify optimal and affordable food patterns would ensure that dietary recommendations can be achieved by all socioeconomic groups.

\section{Conclusion}

Calculating the relative costs of eating healthy is a component of nutrition economics. Dietary recommendations aimed at all socioeconomic strata would benefit from economic feasibility studies.

\section{Acknowledgements}

The paper is based on a presentation at the WALTHAM International Sciences Symposium, Chicago, USA, on 18-21 October 2016.

Analyses were supported by National Institutes of Health grant R01 DK076608.

A. D. has received grants, contracts, honoraria and consulting fees from numerous food and beverage companies and other 
commercial and non-profit entities with interests in diet quality and health. The University of Washington has received grants, donations and contracts from both the public and the private sector.

\section{References}

1. Drewnowski A \& Popkin BM (1997) The nutrition transition: new trends in the global diet. Nutr Rev 55, 2, 31-43.

2. Hawkes C, Smith TG, Jewell J, et al. (2015) Smart food policies for obesity prevention. Lancet 385, 2410-2421.

3. Swinburn BA, Sacks G, Hall KD, et al. (2011) The global obesity pandemic: shaped by global drivers and local environments. Lancet 378, 804-814.

4. Monteiro CA (2009) Nutrition and health. The issue is not food, nor nutrients, so much as processing. Public Health Nutr 12, 729-731.

5. Poti JM, Mendez MA, Ng SW, et al. (2015) Is the degree of food processing and convenience linked with the nutritional quality of foods purchased by us households? Am J Clin Nutr 101, 1251-1262.

6. Drewnowski A \& Specter S (2004) Poverty and obesity: the role of energy density and energy costs. Am J Clin Nutr 79, 6-16.

7. Darmon N \& Drewnowski A (2015) Contribution of food prices and diet cost to socioeconomic disparities in diet quality and health: a systematic review and analysis. Nutr Rev 73, 643-660.

8. World Health Organization Regional Office for Europe (2014) Obesity and inequities; guidance for addressing inequities in overweight and obesity. http://www.Euro.Who.Int/_data/ assets/pdf_file/0003/247638/obesity-090514.Pdf (accessed August 2017).

9. Bes-Rastrollo M, van Dam RM, Martinez-Gonzalez MA, et al. (2008) Prospective study of dietary energy density and weight gain in women. Am J Clin Nutr 88, 769-777.

10. Vergnaud AC, Estaquio C, Czernichow S, et al. (2009) Energy density and 6-year anthropometric changes in a middle-aged adult cohort. Br J Nutr 102, 302-309.

11. Mendoza JA, Drewnowski A \& Christakis DA (2007) Dietary energy density is associated with obesity and the metabolic syndrome in US adults. Diabetes Care 30, 974-979.

12. Wang J, Luben R, Khaw K-T, et al. (2008) Dietary energy density predicts the risk of incident type 2 diabetes: the European Prospective Investigation of Cancer (EPIC)Norfolk Study. Diabetes Care 31, 2120-2125.

13. Hingle MD, Wertheim BC, Neuhouser ML, et al. (2017) Association between dietary energy density and incident type 2 diabetes in the women's health initiative. J Acad Nutr Diet 117, 778-785.

14. US Department of Agriculture Center for Nutrition Policy and Promotion (2012) Dietary energy density and body weight: a review of the evidence. https://www.cnpp.usda.gov/sites/ default/files/nutrition_insights_uploads/Insight50.pdf

15. World Health Organization (2003) Diet, Nutritionand the Prevention of Chronic Diseases. Report of a Joint WHO/FAO Expert Consultation.WHO Technical Report Series, no. 916. Geneva, Switzerland: WHO. http://www.Who.Int/nutrition/ publications/obesity/who_trs_916/en/
16. Maillot M, Darmon N, Darmon M, et al. (2007) Nutrient-dense food groups have high energy costs: an econometric approach to nutrient profiling. J Nutr 137, 1815-1820.

17. Drewnowski A (2005) Concept of a nutritious food: toward a nutrient density score. Am J Clin Nutr 82, 721-732.

18. Rayner M, Scarborough P, Boxer B, et al.. (2005) Nutrient profiles: development of final model. Final report. http:// www.Food.Gov.Uk/multimedia/pdfs/nutprofr.Pdf (accessed December 2016).

19. Drewnowski A \& Fulgoni V 3rd (2008) Nutrient profiling of foods: creating a nutrient-rich food index. Nutr Rev 66, 23-39.

20. Rao M, Afshin A, Singh G, et al. (2013) Do healthier foods and diet patterns cost more than less healthy options? A systematic review and meta-analysis. BMJ Open 3, e004277.

21. Rehm CD, Monsivais P \& Drewnowski A (2015) Relation between diet cost and healthy eating index 2010 scores among adults in the United States 2007-2010. Prev Med 73, 70-75.

22. United States Department of Health and Human Services \& Department of Agriculture (2015) Dietary guidelines for Americans. http://www.Health.Gov/dietaryguidelines/dga 2005/document/default.Htm (accessed December 2016).

23. Drewnowski A (2007) The real contribution of added sugars and fats to obesity. Epidemiol Rev 29, 160-171.

24. Batis C, Rivera JA, Popkin BM, et al. (2016) First-year evaluation of Mexico's tax on nonessential energy-dense foods: an observational study. PLoS Med 13, e1002057.

25. Amoroso L (2016) The second international conference on nutrition: implications for hidden hunger. World Rev Nutr Diet 115, 142-152.

26. Beheshti R, Igusa T \& Jones-Smith J (2016) Simulated models suggest that price per calorie is the dominant price metric that low-income individuals use for food decision making. $J$ Nutr 146, 2304-2311.

27. Schlosser E (2001) Fast Food Nation: The Dark Side of the All-American Meal. New York: Houghton Mifflin.

28. O'Connor A (2017) In the shopping cart of a food stamp household: lots of soda. https://www.Nytimes.Com/2017/ 01/13/well/eat/food-stamp-snap-soda.Html?_r=0 (accessed August 2017).

29. Martinez Steele E, Baraldi LG, Louzada ML, et al. (2016) Ultraprocessed foods and added sugars in the us diet: evidence from a nationally representative cross-sectional study. BMJ Open 6, 2015-009892.

30. Martínez Steele E, Popkin BM, Swinburn B, et al. (2017) The share of ultra-processed foods and the overall nutritional quality of diets in the US: evidence from a nationally representative cross-sectional study. Popul Health Metr 15, 6 .

31. National Cancer Institute \& US National Institutes of Health (2005-2006) Sources of sodium among the US Population. http:// riskfactor.Cancer.Gov/diet/foodsources/sodium/\#methods

32. The Nestlé Company (2014) The Nestlé nutritional profiling system, its product categories and sets of criteria. http:// www.Nestle.Com/asset-library/documents/library/documents/ nutrition_health_wellness/nestle-nutritional-profiling-system.Pdf (accessed August 2017). 